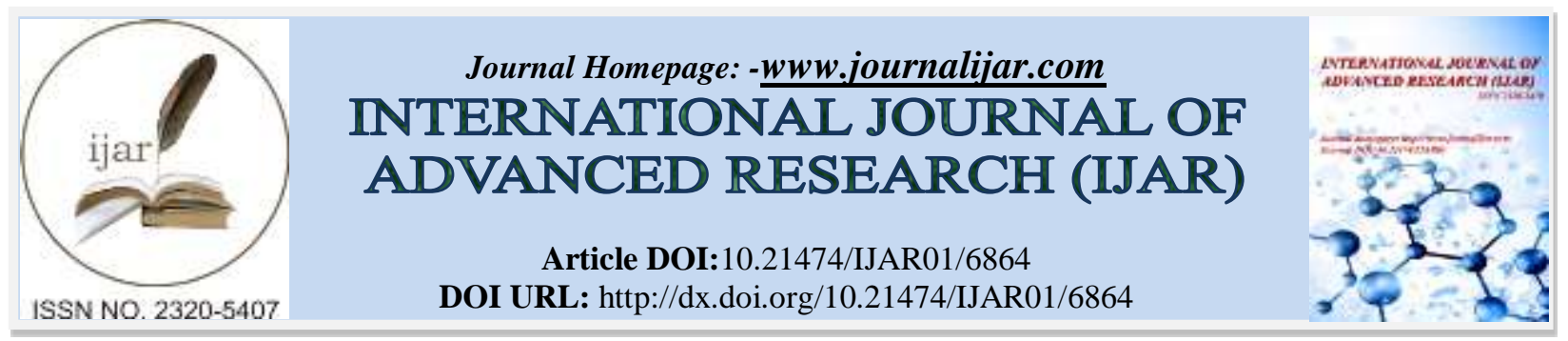

RESEARCH ARTICLE

\title{
EFFECTIVENESS OF REPRODUCTIVE SURROGACY PACKAGE ON LEVEL OF ACCEPTANCE AND PRACTICE AMONG INFERTILE COUPLES -A PILOT STUDY REPORT.
}

\author{
Umamageshwari. K and Prema. K.
}

\section{Manuscript Info}

(..........................

Manuscript History

Received: 06 February 2018

Final Accepted: 08 March 2018

Published: April 2018

Keywords:-

Infertility, Surrogacy, Level Of

Acceptance.

\begin{abstract}
The rate of infertility in the Indian population involves many factors including changes in lifestyle, stress and delayed marriage. A quantitative quasi experimental study was conducted to find the reliability and feasibility of tool and intervention with 34 samples selected through purposive sampling technique for experimental and control group in GG Fertility Centre, Chennai . The couples who fulfilled the inclusion criteria were selected as samples. Demographic data was collected by structured questionnaires. The level of acceptance was assessed by using a three point likert scale and practice was observed. The Reproductive Surrogacy Package (power point presentation, booklet on surrogacy and referring for counseling) was implemented to experimental group (17 couples). After two weeks post test conducted with same questionnaires. The results revealed that the tools used, set criteria for sample selection, the implementation of interventions were highly reliable and feasible for implementation.
\end{abstract}

Copy Right, IJAR, 2018,. All rights reserved.

\section{Introduction:-}

Infertility is an inability to conceive within one year despite having unprotected sexual intercourse. The prevalence of infertility has not changed greatly although more couples are now seeking help than previously. Infertility is categorized as primary if there has been no prior conception and secondary if there has been a previous pregnancy irrespective of the outcome.

Many couples are unable to have their own children. Up until the last couple of decades, those couples had only two alternatives, adoption or remain childless. Today due to advances in reproductive technology, couples now have medical means to have children. Reproductive techniques such as artificial insemination, invitroferilisation/ pre embryo transfer (IVF/ET, also known as test tube babies) and other advanced reproductive technologies allow otherwise infertile couples a chance to have children. However, there are still some couples for whom these techniques are not successful and for whom adoption is not an attractive or viable option. These couples may still wish to have children of their genetic off spring. Often the mother cannot give birth, for reasons that may include lack of uterus or where pregnancy would be medically risky or repeated failure of assisted reproductive technique procedures. For these or other reasons, the only way to have a genetic offspring is to have another woman carry and give birth to their child, a surrogate mother. The couples wishing to obtain a child through a surrogacy arrangement is often referred to in the law as commissioning couple or intended parents. 


\section{Objectves:-}

To test the reliability - feasibility of the tool and reproductive surrogacy package on level of acceptance and practice among infertile couples.

\section{Methodology:-}

Research Approach:-

Quantitative approach was used to evaluate the effectiveness of reproductive surrogacy package.

\section{Research Design:-}

Quasi Experimental Pretest -post test design was used for this research .One experimental group manipulated with reproductive surrogacy package and One control group.

\section{Research Setting:-}

The study was conducted in the out patient department of GG Fertility Centre.

1. It deals with all aspect of fertility research and offers the latest innovative laboratory techniques in the field of assisted production.

2. It was established in 1982, and rendering its services for past 33 years.

3. On an average 100 new out patients come for treatment.

\section{Research Population:-}

Infertile Couples attending OPD at GG Fertility Centre, Chennai.

\section{Sample:-}

The infertile couples attending OPD at selected fertility Centre who fulfills the inclusion criteria and were available during the data collection period.

\section{Sample size:-}

The sample size is 34 as determined by power analysis. In that total samples, 17 samples selected for experimental group and 17 samples for control group.

\section{Sampling techniques:-}

Samples were selected using non probability purposive sampling technique

\section{Sampling criteria:-}

\section{Inclusion Criteria:-}

1. Couples with infertility for five or more years with two or more failure in IVF treatment

2. Couples who know to read and write tamil or english or both

3. Couples who are willing to participate in the study

4. Indian couples.

\section{Exclusion Criteria:-}

Single person attending OPD without their partner.

\section{Tools And Description:-}

Part I:-Structured questionnaire for demographic variables.

Part II:-Three point likert scale for level of acceptance.

Part III:- Structured questionnaire for practice of surrogacy.

\section{Results and Discussion:-}

For questionnaire test retest method was adopted and the tool reliability was assessed by spearman brown's formula.

The tool reliability score "r" was 0.86 and the tool was highly reliable for assessing level of acceptance and practice of surrogacy among infertile couples. 
Data were analyzed using descriptive statistics mean and standard deviation, inferential statistics unpaired t test to assess the level of acceptance and practice of surrogacy among infertile couples.

Table1:

Level Of Acceptance Of Surrogacy:- (Experimentalgroup)

\begin{tabular}{|l|c|c|c|c|}
\hline $\begin{array}{l}\text { LEVEL OF } \\
\text { ACCEPTANCE }\end{array}$ & \multicolumn{2}{|c|}{ PRE - TEST } & \multicolumn{2}{c|}{ POST - TEST } \\
\hline & (n) & \% & 9 & $\mathbf{4 8 . 5 7 \%}$ \\
\hline ADEQUATE & 1 & $\mathbf{5 . 7 \%}$ & $\mathbf{6}$ & $\mathbf{2 2 . 8 \%}$ \\
\hline MODERATE & $\mathbf{3}$ & $\mathbf{1 1 . 4 \%}$ & $\mathbf{2}$ & $\mathbf{2 8 . 5 7 \%}$ \\
\hline INADEQUATE & $\mathbf{1 3}$ & $\mathbf{8 2 . 8 \%}$ & & \\
\hline
\end{tabular}

Table 2:

Level Of Acceptance Of Surrogacy:- (control group)

\begin{tabular}{|l|c|c|c|c|}
\hline $\begin{array}{l}\text { LEVEL OF } \\
\text { ACCEPTANCE }\end{array}$ & $(\mathrm{n})$ & $\%$ & (n) & POST - TEST \\
\hline ADEQUATE & 1 & $\mathbf{5 . 7 \%}$ & $\mathbf{1}$ & $\mathbf{3}$ \\
\hline MODERATE & $\mathbf{2}$ & $\mathbf{1 0 . 4 \%}$ & $\mathbf{3}$ & $\mathbf{1 1 . 4 \%}$ \\
\hline INADEQUATE & $\mathbf{1 4}$ & $\mathbf{8 3 . 8 \%}$ & $\mathbf{8 2 . 8 \%}$ \\
\hline
\end{tabular}

Practice Of Surrogacy:-

Out of 34 infertile couples 2 couples adopted surrogacy (5.7\%). (In experimental group only).

\section{Discussion:-}

The main focus of this study was to test the reliability and feasibility of the data collection tools and intervention and its acceptability and effectiveness of reproductive surrogacy package on level of acceptance and practice of surrogacy among infertile couples. The results indicated that tools used were highly reliable.

The pilot study also showed that the sampling technique, set inclusion and exclusion criteria were appropriate for sample selection. The teaching methods selected and the proposed analytical measures were suitable for the study. The comparison between the groups showed that there was a statistical significance. The overall plan was effective, feasible and practicable to be applied in the main study.

\section{Conclusion:-}

The pilot study on the effectiveness of reproductive surrogacy package on level of acceptance and practice of surrogacy among infertile couples.

The Data collection tools used were reliable, feasible and appropriate to be applied to the samples in the main study and the reproductive surrogacy package was effective on level of acceptance of surrogacy among infertile couples but not on practice of surrogacy.

\section{References:-}

1. Surrogacy in India(www.surrogacy clinics.com/India surrogacy journey.

2. Surrogate mother | Define Surrogate mother at Dictionary.com http://dictionary.reference.com/browse/surrogate+mothe

3. Art regulation bill 2010http://www.scribd.com/doc/33533932/Art-Regulation-Draft-Bill1-India?

4. http://dictionary.reverso.net/english-definition/surrogate\%20family

5. http://childbirthsolutions.com/articles/traditional-versus-gestational-surrogacy/

6. http://ivftreatmentindia.wordpress.com/

7. http://www.mentalhelp.net/poc/view_doc.php?id=3732\&type=book\&cn=5

8. http://www.unicef.org/about/history/files/Child-First-CH-03-p063-090-unravel-nutrition-com... 